Check for updates

Cite this: RSC Adv., 2017, 7, 20231

Received 22nd February 2017

Accepted 1st April 2017

DOI: $10.1039 / c 7 r a 02204 b$

rsc.li/rsc-advances

\title{
Microwave-assisted synthesis of cobalt sulphide nanoparticle clusters on activated graphene foam for electrochemical supercapacitors
}

\author{
Tshifhiwa Moureen Masikhwa, Moshawe Jack Madito, Abdulhakeem Bello, \\ Joel Lekitima and Ncholu Manyala (D)*
}

\begin{abstract}
Cobalt sulphide $\left(\mathrm{Co}_{9} \mathrm{~S}_{8}\right)$ nanoparticle clusters embedded in an activated graphene foam (AGF) structure were prepared using microwave-assisted hydrothermal synthesis. Morphological characterization of the as-prepared $\mathrm{Co}_{9} \mathrm{~S}_{8} / \mathrm{AGF}$ showed that $\mathrm{Co}_{9} \mathrm{~S}_{8}$ composed of cluster (sphere)-like nanoparticles was embedded in the matrix of a porous sheet-like AGF. The synergy between the $\mathrm{Co}_{9} \mathrm{~S}_{8}$ nanoparticles and AGF in the $\mathrm{CO}_{9} \mathrm{~S}_{8} / \mathrm{AGF}$ composite showed predominantly an improvement in the porous nature (surface area and pore volume) of the $\mathrm{CO}_{9} \mathrm{~S}_{8}$ and the electrical conductivity of the composite electrode. The composite exhibited a specific capacitance of $1150 \mathrm{~F} \mathrm{~g}^{-1}$ as compared to $\mathrm{Co}_{9} \mathrm{~S}_{8}$ with a specific capacitance of $507 \mathrm{~F} \mathrm{~g}^{-1}$ at a scan rate of $5 \mathrm{mV} \mathrm{s}^{-1}$ and good cycling stability in $6 \mathrm{M} \mathrm{KOH}$ electrolyte. The $\mathrm{Co}_{9} \mathrm{~S}_{8} / \mathrm{AGF}$ composite showed significant improvement in the specific capacitance compared to pure $\mathrm{Co}_{9} \mathrm{~S}_{8}$ and specific capacitance values found in previously published reports by other studies for cobalt sulphide-based composites.
\end{abstract}

\section{Introduction}

The constantly increasing energy and power demands in energy storage applications have caused important research exertions on the improvement of new electrode materials for advanced energy storage devices. The main electrode materials for electrical double layer capacitors (EDLCs) are carbon based materials and faradic materials, such as transitional metal oxide/ hydroxides, transition metal disulphides and conducting polymers, which are explored for redox or hybrid based supercapacitors. ${ }^{1-3}$ EDLCs with good conductivity and a tunable porous network can deliver a long cycle life but relatively low energy density which is necessary for various supercapacitor applications. In contrast, faradic based materials show higher capacitance than EDLCs due to their fast, reversible electrosorption and redox processes occurring on the electrode surface. Therefore, increasingly, study on electrochemical capacitors has been focused on combining the unique advantages of different capacitive materials for better electrochemical performance. ${ }^{4}$ Recently, porous carbon materials such as activated carbon (AC) have been used as electrode materials in the production of EDLCs due to their good electrical conductivities, long cycle-life and large surface area. ${ }^{5-8}$

Transition metal chalcogenides such as cobalt sulphide, ${ }^{9-11}$ molybdenum disulphide, ${ }^{12-14}$ nickel sulphide, ${ }^{15-17}$ and copper

Department of Physics, Institute of Applied Materials, SARCHI Chair in Carbon Technology and Materials, University of Pretoria, Pretoria 0028, South Africa. E-mail: ncholu.manyala@up.ac.za; Fax: +27 12420 2516; Tel: +27 124203549 sulphide $^{18}$ are potential electrode materials for supercapacitor applications because they are known to be electrochemically active. However, cobalt sulphide which exists in different stoichiometric ratios like $\mathrm{Co}_{1-x} \mathrm{~S}, \mathrm{CoS}, \mathrm{CoS}_{2}, \mathrm{Co}_{9} \mathrm{~S}_{8}$, and $\mathrm{Co}_{3} \mathrm{~S}_{4}$, is considered to be a suitable candidate for electrochemical supercapacitor applications due to its good electrochemical activity, high thermal conductivity, and low cost compared to other metal sulphides. Amongst different cobalt sulphide stoichiometries, $\mathrm{Co}_{9} \mathrm{~S}_{8}$ is a typical transitional metal chalcogenide which has great potential in battery and supercapacitor application. ${ }^{11,19}$ However, the poor electrical conductivity and mechanical instability of $\mathrm{Co}_{9} \mathrm{~S}_{8}$ limit its energy storage application. In order to improve the properties of $\mathrm{Co}_{9} \mathrm{~S}_{8}$, its various nanostructures have been investigated, for example, 3D flowerlike, nanoflakes, nanotubes and rose-like structures. ${ }^{20-25}$ It has been established that modifying the $\mathrm{Co}_{9} \mathrm{~S}_{8}$ with carbon materials by preparing $\mathrm{Co}_{9} \mathrm{~S}_{8} /$ carbon composites is one of the most effective strategies to increase the electrical conductivity as well as the electrochemical properties of $\mathrm{Co}_{9} \mathrm{~S}_{8}$. Carbon materials provide interconnecting mesostructured supports that can facilitate good nanoparticle dispersion and electron transport. For example, Ramachandran et al. have produced $\mathrm{Co}_{9} \mathrm{~S}_{8}$ nanoflakes on graphene to form $\mathrm{Co}_{9} \mathrm{~S}_{8} / \mathrm{G}$ nanocomposites, for highperformance supercapacitors. ${ }^{21}$ So far no work has been done on the microwave-assisted hydrothermal synthesis of $\mathrm{Co}_{9} \mathrm{~S}_{8}$ nanoparticles clusters on activated graphene foam (AGF) derived from polymer-based materials in an aqueous electrolyte media for electrochemical supercapacitor application. 
Herein, we report a microwave-assisted hydrothermal synthesis of $\mathrm{Co}_{9} \mathrm{~S}_{8}$ nanoparticles clusters on a porous sheet-like AGF derived from polymer-based materials in an aqueous electrolyte media. Microwave-assisted hydrothermal synthesis is a promising preparation method since the microwave synthesis process consists of high reaction rate and fast heating, and is capable of reducing reaction time drastically and saving energy thus lowering the cost of final product. In addition, microwave-assisted hydrothermal synthesis also has many other unique advantages, such as the homogeneous volumetric heating, the high penetration depth of microwave, and high selectivity. We also explore the potential of the composite as an electrode for supercapacitor applications. An electrochemical performance of as-prepared $\mathrm{Co}_{9} \mathrm{~S}_{8}$ and $\mathrm{Co}_{9} \mathrm{~S}_{8} / \mathrm{AGF}$ electrodes was evaluated in a three-electrode cell configuration using $6 \mathrm{M}$ $\mathrm{KOH}$. The specific capacitance of $\mathrm{Co}_{9} \mathrm{~S}_{8} / \mathrm{AGF}$ electrode was obtained as $1150 \mathrm{~F} \mathrm{~g}^{-1}$ and that of the $\mathrm{Co}_{9} \mathrm{~S}_{8}$ electrode as $507 \mathrm{~F} \mathrm{~g}^{-1}$ at a scan rate of $5 \mathrm{mV} \mathrm{s}^{-1}$. $\mathrm{Co}_{9} \mathrm{~S}_{8} / \mathrm{AGF}$ electrode showed a good cycling stability with $94 \%$ capacitance retention over 1000 charge-discharge cycles.

\section{Experimental}

\section{Materials}

Cobalt(II) nitrate hexahydrate $\left(\mathrm{Co}\left(\mathrm{NO}_{3}\right)_{2} \cdot 6 \mathrm{H}_{2} \mathrm{O}\right.$, purity $\left.>99.99 \%\right)$, hydrochloric acid $(\mathrm{HCl}, \geq 32 \%)$, thiourea $\left(\mathrm{CH}_{4} \mathrm{~N}_{2} \mathrm{~S}\right.$, purity $\geq 99 \%$ ) and polyvinyl alcohol (PVA, 99+\% hydrolyzed) were purchased from Sigma-Aldrich. Polycrystalline Ni foam (3D scaffold template with an areal density of $420 \mathrm{~g} \mathrm{~m}^{2}$ and with a thickness of $1.6 \mathrm{~mm}$ ) was purchased from Alantum (Munich, Germany). Potassium hydroxide ( $\mathrm{KOH}, \min 85 \%)$ was purchased from Merck (South Africa).

\section{Synthesis of activated graphene foam}

The graphene foam (GF) was prepared using CVD and polycrystalline Ni foam substrate placed at a centre of a CVD quartz tube. GF was grown at $1000{ }^{\circ} \mathrm{C}$ for $10 \mathrm{~min}$ under a mixture of argon (Ar), hydrogen $\left(\mathrm{H}_{2}\right)$ and methane $\left(\mathrm{CH}_{4}\right)$ gases at flow rates of 300,200 and $10 \mathrm{sccm}$ respectively. After growth, the graphene/nickel foam samples were rapidly cooled by pushing the quartz tube to lower temperature region of the furnace. After removing the samples from CVD at room temperature, the samples were dipped in $3 \mathrm{M} \mathrm{HCl}$ at $80{ }^{\circ} \mathrm{C}$ to etch nickel foam. After complete etching of the nickel, the recovered GF was washed several times with deionized water and dried at $60{ }^{\circ} \mathrm{C}$.

Furthermore, GF was activated to produce porous activated graphene foam (AGF) as follows: a hydrogel was synthesised by dispersing a $100 \mathrm{mg}$ of GF in $0.1 \mathrm{~g} \mathrm{ml}^{-1}$ of polyvinyl alcohol (PVA) in a vial glass by ultrasonication followed by addition of $1.5 \mathrm{ml}$ of hydrochloric acid $(\mathrm{HCl})$ to the solution. The resultant mixture was hydrothermally treated in a sealed Teflon-lined stainless-steel autoclave at a temperature of $190{ }^{\circ} \mathrm{C}$ for $12 \mathrm{~h}$ to polymerize the mixture, and then cooled to room temperature. The recovered product, hydrogel, was washed with deionized water and dried for $6 \mathrm{~h}$. Furthermore, the as-prepared hydrogel was soaked in aqueous $\mathrm{KOH}$ solution $(\mathrm{KOH} /$ hydrogel mass ratio
= 7) for $24 \mathrm{~h}$, and then the $\mathrm{KOH} /$ hydrogel mixture was placed in a horizontal tube furnace (for activation) and heated up to $800{ }^{\circ} \mathrm{C}$ at heating rate of $10{ }^{\circ} \mathrm{C} \mathrm{min}^{-1}$ under argon gas flow for $1 \mathrm{~h}$. Finally, the recovered AGF was neutralized with $0.1 \mathrm{ml}$ of $\mathrm{HCl}$, washed with deionised water and dried at $120^{\circ} \mathrm{C}$ for $12 \mathrm{~h}$. A detailed preparation and characterization of AGF is given by Bello et al. ${ }^{26}$

\section{Synthesis of $\mathrm{Co}_{9} \mathrm{~S}_{8}$ and $\mathrm{Co}_{9} \mathrm{~S}_{8} /$ AGF composite using microwave-assisted approach}

In the synthesis of $\mathrm{Co}_{9} \mathrm{~S}_{8}$, all the chemical reagents were used without any further purification. A $0.3 \mathrm{mmol}$ of $\mathrm{Co}\left(\mathrm{NO}_{3}\right)_{2} \cdot 6 \mathrm{H}_{2} \mathrm{O}$ was dissolved in $30 \mathrm{ml}$ of deionized water under vigorous stirring for $20 \mathrm{~min}$, then a $0.6 \mathrm{mmol}$ thiourea $\left(\mathrm{CH}_{4} \mathrm{~N}_{2} \mathrm{~S}\right)$ was added to this solution and the mixture was further stirred for $30 \mathrm{~min}$. After stirring, the mixture was carefully transferred into a quartz vessel in a microwave reactor (Anton Paar Synthos 3000 multimode reactor, $1400 \mathrm{~W}$ magnetron power) equipped with a wireless pressure and temperature sensor. The reactor was operated in the pressure mode using a power of $700 \mathrm{~W}$; the sample temperature was ramped at a heating rate of $10{ }^{\circ} \mathrm{C}$ $\min ^{-1}$ to $160{ }^{\circ} \mathrm{C}$ and maintained for $30 \mathrm{~min}$ at a pressure of 8.0 $\times 10^{6} \mathrm{~Pa}$. Finally, after cooling the reaction chamber to room temperature the recovered product was filtered and washed several times with deionized water and ethanol, and dried at $60{ }^{\circ} \mathrm{C}$ for $6 \mathrm{~h}$ to obtain $\mathrm{Co}_{9} \mathrm{~S}_{8}$ nanoparticles clusters.

Similar to the synthesis of $\mathrm{Co}_{9} \mathrm{~S}_{8}$, the $\mathrm{Co}_{9} \mathrm{~S}_{8} / \mathrm{AGF}$ composite was prepared using a microwave reactor as demonstrated in Scheme 1. In the synthesis of $\mathrm{Co}_{9} \mathrm{~S}_{8} / \mathrm{AGF}$ composite, a $15 \mathrm{mg}$ of AGF was dispersed in $30 \mathrm{ml}$ of water by ultrasonication for $12 \mathrm{~h}$ at room temperature. Thereafter, a $0.3 \mathrm{mmol}$ of $\mathrm{Co}\left(\mathrm{NO}_{3}\right)_{2} \cdot 6 \mathrm{H}_{2} \mathrm{O}$ and $0.6 \mathrm{mmol}$ of $\mathrm{CH}_{4} \mathrm{~N}_{2} \mathrm{~S}$ was added to the AGF solution and the mixture was stirred for $10 \mathrm{~min}$. After stirring, the mixture was transferred into a quartz vessel in a microwave reactor and the reactor settings used for the synthesis of $\mathrm{Co}_{9} \mathrm{~S}_{8}$ as discussed above were repeated. After natural cooling of the reaction chamber to room temperature, the recovered product was filtered and washed several times with deionized water and ethanol, and dried at $60{ }^{\circ} \mathrm{C}$ for $6 \mathrm{~h}$ to obtain $\mathrm{Co}_{9} \mathrm{~S}_{8} / \mathrm{AGF}$ composite which shows $\mathrm{Co}_{9} \mathrm{~S}_{8}$ nanoparticles clusters on AGF as seen from a micrograph in Scheme 1.

\section{Structural and morphological characterization}

$\mathrm{X}$-ray diffraction (XRD) analysis of AGF, as-prepared $\mathrm{Co}_{9} \mathrm{~S}_{8}$ and $\mathrm{Co}_{9} \mathrm{~S}_{8} / \mathrm{AGF}$ composite was carried out using XPERT-PRO diffractometer (PANalytical BV, Netherlands) with theta/2 theta geometry, operating with a cobalt tube at $50 \mathrm{kV}$ and 30 mA. Raman spectroscopy analysis was carried out using a Jobin Yvon Horiba TX 6400 micro-Raman spectrometer and the samples were analyzed using a $514 \mathrm{~nm}$ excitation laser and 1.5 $\mathrm{mW}$ laser power on the sample to avoid possible thermal effects and beam damage. X-ray photoelectron spectroscopy (XPS) measurements of the samples were conducted using a Physical Electronics VersaProbe 5000 spectrometer operating with a 100 $\mu \mathrm{m}$ monochromatic Al-K $\alpha$ exciting source. The SEM images were obtained using a Zeiss Ultra Plus 55 field emission 


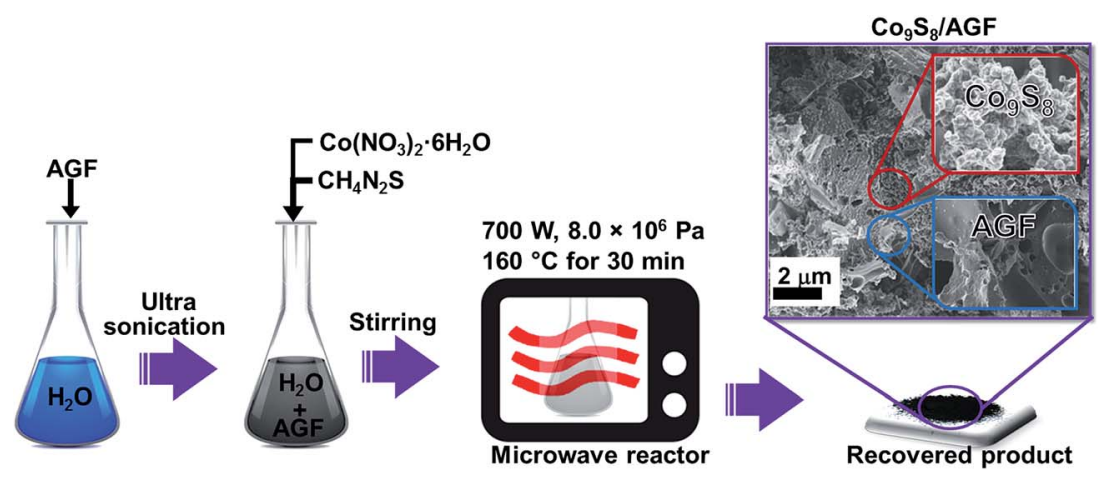

Scheme 1 Preparation procedure of $\mathrm{CO}_{9} \mathrm{~S}_{8}$ and its composite with AGF which shows $\mathrm{Co}_{9} \mathrm{~S}_{8}$ nanoparticles clusters on AGF in the scanning electron microscope (SEM) micrograph.

scanning electron microscope (FE-SEM) operated at an accelerating voltage of $2.0 \mathrm{kV}$.

For high-resolution transmission electron microscopy (HRTEM) and the energy-dispersive X-ray spectrometer (EDS) spectra analysis the ethanol solution containing the asprepared materials was dispersed on a formal-coated copper grid and the analysis was carried out on a Jeol JEM-2100F Field Emission Electron Microscope with a maximum analytical resolution of $200 \mathrm{kV}$ and a probe size of $<0.5 \mathrm{~nm}$.

\section{Electrode preparation and electrochemical characterization}

The working electrodes were prepared as follows: $85 \mathrm{wt} \%$ of the $\mathrm{Co}_{9} \mathrm{~S}_{8} /$ AGF material was mixed with $10 \mathrm{wt} \%$ carbon black and 5 wt $\%$ polyvinylidene difluoride (PVDF) binder in an agate mortar. The mixture was then dissolved with 1-methyl-2pyrrolidinone (NMP) to form a paste. Thereafter, a paste was coated homogeneously on $\mathrm{Ni}$ foam which served as a current collector and dried at $60{ }^{\circ} \mathrm{C}$ for $8 \mathrm{~h}$ to ensure complete evaporation of the NMP. The estimated mass per electrode after drying is $2.5 \mathrm{mg}$.

The electrochemical properties were investigated using a Bio-Logic VMP300 potentiostat (Knoxville TN 37930, USA) controlled by the EC-Lab ${ }^{\circledR}$ V10.40 software in a three-electrode configuration. The $\mathrm{Co}_{9} \mathrm{~S}_{8} / \mathrm{AGF}$ material served as the working electrode, glassy carbon plate as the counter electrode and $\mathrm{Ag} /$ $\mathrm{AgCl}(3 \mathrm{M} \mathrm{KCl})$ as the reference electrode. A $6 \mathrm{M}$ potassium hydroxide (KOH) electrolyte was used for analysis. The cyclic voltammetry $(\mathrm{CV})$ tests were carried out in the potential window range of 0.0 to $0.6 \mathrm{~V} v s$. $\mathrm{Ag} / \mathrm{AgCl}$ at different scan rates ranging from 5 to $100 \mathrm{mV} \mathrm{s}^{-1}$. The electrochemical impedance spectroscopy (EIS) measurements were performed in the open circuit within a frequency range of $10 \mathrm{mHz}$ to $100 \mathrm{kHz}$.

\section{Results and discussion}

\section{Structural and morphological characterization}

Fig. 1(a) shows the XRD patterns of the as-prepared AGF, $\mathrm{Co}_{9} \mathrm{~S}_{8}$ and $\mathrm{Co}_{9} \mathrm{~S}_{8} / \mathrm{AGF}$ composite. The typical diffraction peaks corresponding to $\mathrm{Co}_{9} \mathrm{~S}_{8}$ were indexed using the best matching Inorganic Crystal Structure Database (ICSD) card number 23929 (crystal system: cubic; space-group: $F m \overline{3} m$ and lattice parameter: $a=9.928 \AA$ ), and ICSD card number 31170 (crystal system: hexagonal, space-group: $P 63 m c$ and cell parameters: $a=$ $2.470 \AA, c=6.790 \AA, a / b=1.000, b / c=1.000$ and $c / a=1.000$ ) for AGF. XRD pattern of the composite shows well-defined crystalline peaks with different diffraction planes suggesting that the as-prepared $\mathrm{Co}_{9} \mathrm{~S}_{8}$ nanoparticles clusters are polycrystalline with good crystallinity. A (002) peak at $31.2^{\circ}$ which corresponds to AGF confirms the presence of AGF in the composite.

In a view of a molecular structure of $\mathrm{Co}_{9} \mathrm{~S}_{8}$, Fig. 1(b) was obtained using ICSD card number 23929 and diamond crystal structure software. Fig. 1(b) shows a $\mathrm{Co}_{9} \mathrm{~S}_{8}$ molecule viewed in (004) plane and the molecule depicts that the arrangement of the $\mathrm{S}$ atoms around the Co completes a tetrahedron ( $\mathrm{S}$ atoms at 2.13 and $2.21 \AA$ ) and octahedron coordination ( $\mathrm{S}$ atoms at 2.39 A) for each of the Co atoms, and Co-Co interatomic distances is $2.51 \AA$ which is slightly higher than those of Co-S suggesting that $\mathrm{Co}-\mathrm{S}$ bond is more energetically favourable in the molecule. ${ }^{27}$ In Fig. 1(b), it can be seen that $\mathrm{S}$ dominates the edges of the $\mathrm{Co}_{9} \mathrm{~S}_{8}$ molecule which are most likely to be the active sites hence making $\mathrm{S}$ an active site for chemical interaction between the $\mathrm{Co}_{9} \mathrm{~S}_{8}$ and the carbon (C) from AGF during composite synthesis, as demonstrated by arrows. Both C (in graphene) and $\mathrm{S}$ are known to be reactive mainly due to unpaired $\pi$-electron in $\mathrm{C}$ and high electronegativity of $\mathrm{S}$, hence a chemical interaction between $\mathrm{C}$ and $\mathrm{S}$ in $\mathrm{Co}_{9} \mathrm{~S}_{8} / \mathrm{AGF}$ would have occurred during composite synthesis leading to a material with dominating metallic behaviour. ${ }^{28}$ Fig. 1 (c) shows the Raman spectra of the as-prepared AGF, $\mathrm{Co}_{9} \mathrm{~S}_{8}$ and $\mathrm{Co}_{9} \mathrm{~S}_{8} / \mathrm{AGF}$ composite. In the Raman spectrum of the as-prepared $\mathrm{Co}_{9} \mathrm{~S}_{8} / \mathrm{AGF}$, the bands at $586 \mathrm{~cm}^{-1}$ and $1110 \mathrm{~cm}^{-1}$ arise from $\mathrm{Co}_{9} \mathrm{~S}_{8}$ vibrational modes and low-intensity features at $1384 \mathrm{~cm}^{-1}$ and $1583 \mathrm{~cm}^{-1}$ are AGF signatures which agree well with the bands observed from the as-prepared AGF and $\mathrm{Co}_{9} \mathrm{~S}_{8}$ confirming the presence of both AGF and $\mathrm{Co}_{9} \mathrm{~S}_{8}$ in the composite.

The surface elemental composition of the as-prepared $\mathrm{Co}_{9} \mathrm{~S}_{8}$ and $\mathrm{Co}_{9} \mathrm{~S}_{8} / \mathrm{AGF}$ composite was analyzed by XPS. Fig. 2(a) and (b) show the wide scan XPS spectra of the as-received $\mathrm{Co}_{9} \mathrm{~S}_{8}$ and $\mathrm{Co}_{9} \mathrm{~S}_{8} / \mathrm{AGF}$ composite respectively, which displays the main elements (Co, S, and C) of the composition of the samples. The presence of $\mathrm{O}$ and $\mathrm{C}$ elements in the XPS spectrum of $\mathrm{Co}_{9} \mathrm{~S}_{8}$ may be due to the surface-adsorbed $\mathrm{CO}_{2}$ and $\mathrm{O}_{2}$. Similarly, the $\mathrm{O}$ in 

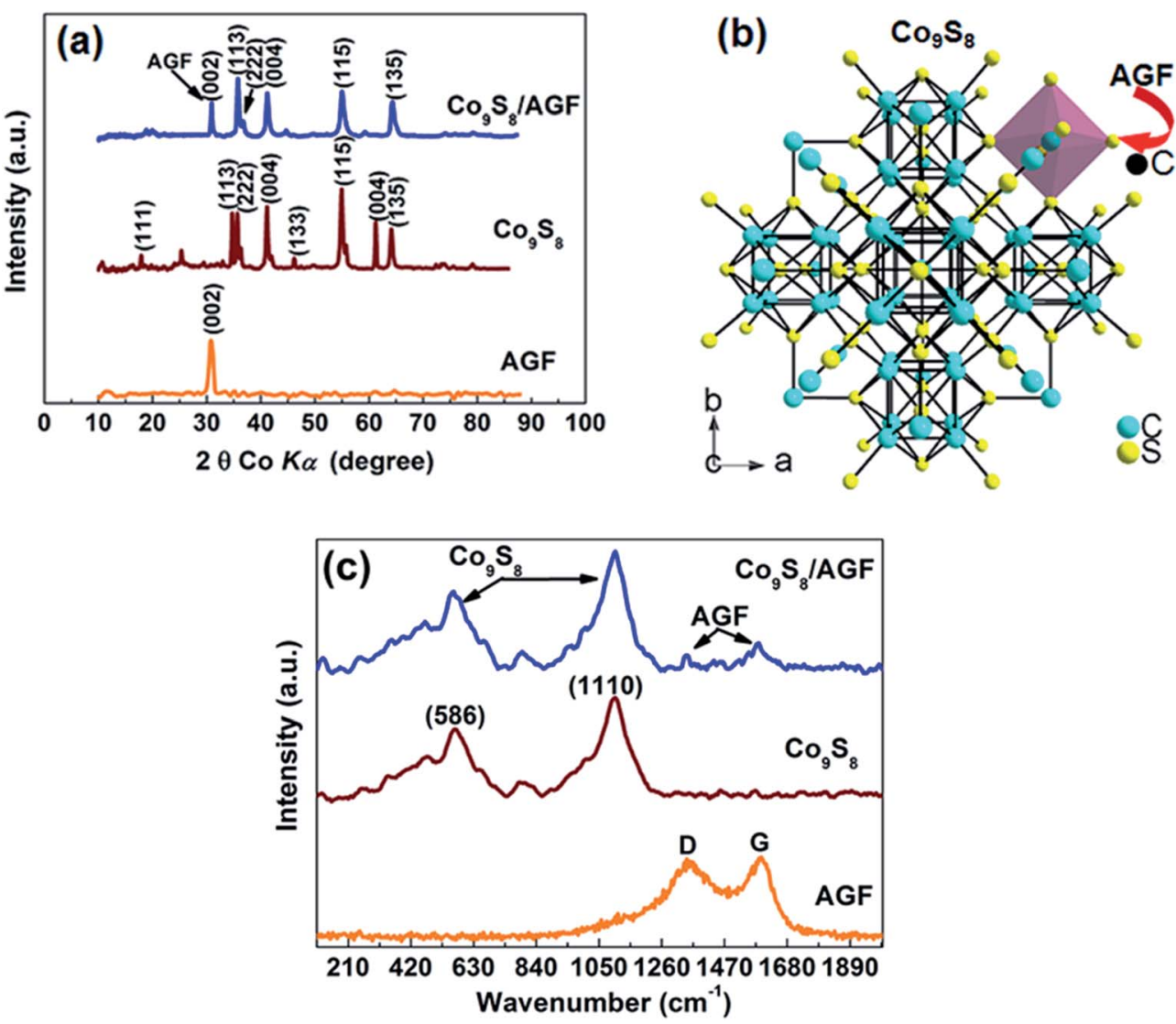

Fig. 1 (a) The XRD of the as-prepared AGF, $\mathrm{Co}_{9} \mathrm{~S}_{8}$ and $\mathrm{Co}_{9} \mathrm{~S}_{8} / \mathrm{AGF}$ composite and the matching ICSD cards. (b) $\mathrm{Co}_{9} \mathrm{~S}_{8}$ molecule viewed in (004) plane. (c) Raman spectra of the as-prepared AGF, $\mathrm{CO}_{9} \mathrm{~S}_{8}$ and $\mathrm{Co}_{9} \mathrm{~S}_{8} / \mathrm{AGF}$ composite.

the XPS spectrum of the composite could be due to the surfaceadsorbed $\mathrm{CO}_{2}$ and $\mathrm{O}_{2}$. A $\mathrm{Co}_{9} \mathrm{~S}_{8}$ sample shows 40.1 at $\%$ of $\mathrm{Co} 2 \mathrm{p}$, 37.2 at $\% \mathrm{~S} 2 \mathrm{p}, 8.2$ at $\% \mathrm{C} 1 \mathrm{~s}$ and 14.5 at $\% \mathrm{O} 1 \mathrm{~s}$ suggesting that a sample is predominantly composed of Co and S. On the other hand, a composite sample shows 22.4 at $\%$ of Co 2 p, 25.6 at $\% \mathrm{~S}$ 2p, 41.7 at\% C 1s and 10.3 at\% O 1s. A high concentration of C suggests that a surface of the composite sample is predominantly C.

Fig. 3(a) and (b) show the SEM images of the as-prepared $\mathrm{Co}_{9} \mathrm{~S}_{8}$ sample at low and high magnifications respectively. A high magnification SEM image of the as-prepared $\mathrm{Co}_{9} \mathrm{~S}_{8}$ sample
(Fig. 3(b)) shows that the product is composed of clustered nanoparticles.

Fig. 3(c) and (d) show the SEM micrographs of the asprepared AGF, and the morphology of this sample reveal the large density of interconnected porous cavities which will provide sufficient reservoirs for an electrolyte. The nanoparticles clusters in $\mathrm{Co}_{9} \mathrm{~S}_{8} / \mathrm{AGF}$ composite are densely anchored on the surface of the AGF as shown in Fig. 3(e) and (f) which show the SEM images of the as-prepared $\mathrm{Co}_{9} \mathrm{~S}_{8} / \mathrm{AGF}$ sample at low and high magnifications respectively. During the composite synthesis reaction, the nuclei formation and crystal growth of
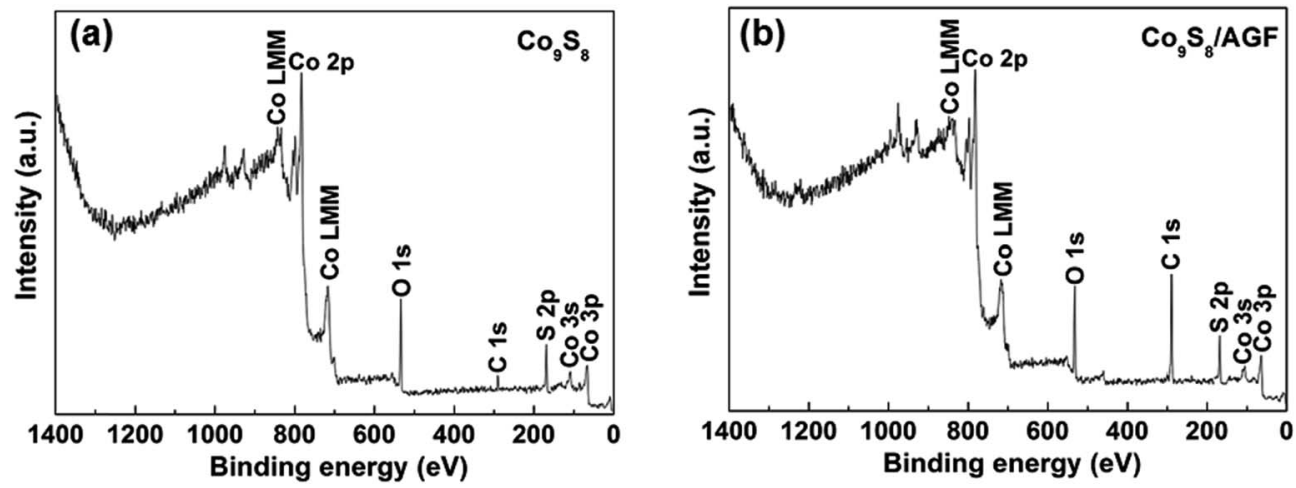

Fig. 2 The wide scan XPS spectra of the as-received (a) $\mathrm{Co}_{9} \mathrm{~S}_{8}$ and (b) $\mathrm{Co}_{9} \mathrm{~S}_{8} / \mathrm{AGF}$ composite. 

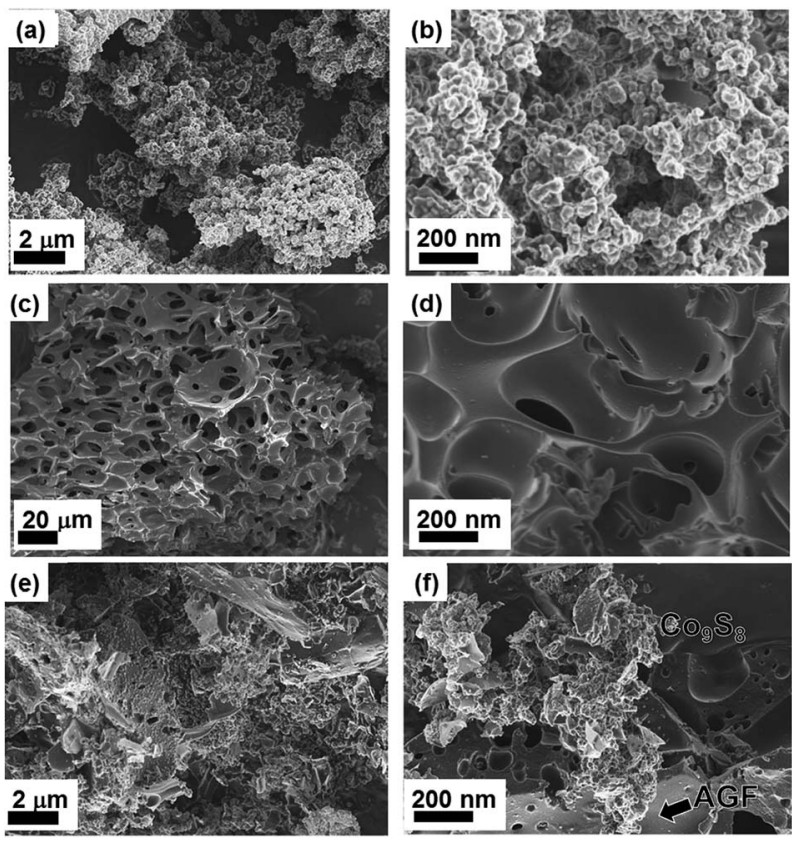

Fig. 3 (a) and (b) SEM images of the as-prepared $\mathrm{CO}_{9} \mathrm{~S}_{8}$ sample at low and high magnifications respectively, (c) and (d) SEM images of the asprepared AGF sample at low and high magnifications respectively, (e) and (f) SEM images of the as-prepared $\mathrm{CO}_{9} \mathrm{~S}_{8} / \mathrm{AGF}$ sample at low and high magnifications respectively.

$\mathrm{Co}_{9} \mathrm{~S}_{8}$ nanoparticles with similar shape and size are attributable to the constant heating by the microwave irradiation. Generally, the reaction kinetics is fast in microwave synthesis owing to the high depth penetration of microwave irradiation, hence uniform-sized nanoparticles could be obtained. ${ }^{29}$

The morphology of the obtained $\mathrm{Co}_{9} \mathrm{~S}_{8}$ with and without AGF were also examined by TEM, as shown in Fig. 4(a) and (b) respectively. These TEM images confirm the observation made under SEM that $\mathrm{Co}_{9} \mathrm{~S}_{8}$ is anchored in the AGF matrix. The nanostructures of the samples seen in TEM images were dispersed on the TEM copper grids. The EDS analysis is shown
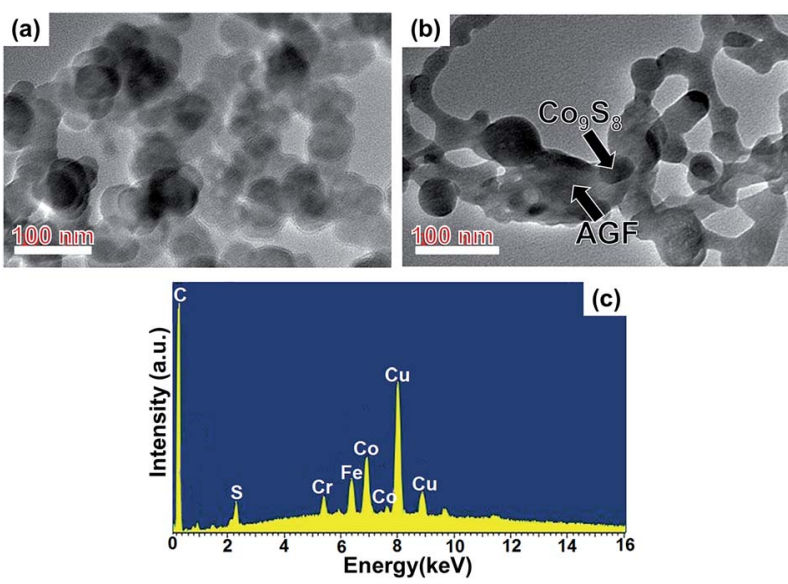

Fig. 4 (a) and (b) TEM images of the as-prepared $\mathrm{Co}_{9} \mathrm{~S}_{8}$ and $\mathrm{CO}_{9} \mathrm{~S}_{8} /$ AGF samples respectively. (c) EDS spectra of the as-prepared $\mathrm{CO}_{9} \mathrm{~S}_{8} /$ AGF sample. in Fig. 4(c) as carried out inside TEM system and confirms the presence of $\mathrm{C}$, Co, and $\mathrm{S}$ in the $\mathrm{Co}_{9} \mathrm{~S}_{8} / \mathrm{AC}$ composite. Additional elements (Fe, $\mathrm{Cu}, \mathrm{Cr}$ ) observed in Fig. 4(c) arise from the TEM copper grid.

The nitrogen adsorption-desorption isotherm of the $\mathrm{Co}_{9} \mathrm{~S}_{8}$ shows a type III behaviour (Fig. 5(a)), indicating a weak interaction between the $\mathrm{N}_{2}$ adsorbent and the material. Furthermore, inset to Fig. 5(a) shows a pore size distribution ranging from 2 to $4 \mathrm{~nm}$ suggesting that pores in $\mathrm{Co}_{9} \mathrm{~S}_{8}$ are mainly mesopores. Fig. 5(b) shows the $\mathrm{N}_{2}$ adsorption-desorption isotherm of the as-prepared AGF which displays a type IV adsorption-desorption with $\mathrm{H} 4$ hysteresis isotherm. Inset to Fig. 5(b) shows a pore size distribution below $3 \mathrm{~nm}$ which is an indication of the existence of micropore in the AGF sample.

On the other hand, the $\mathrm{N}_{2}$ adsorption-desorption isotherm of the $\mathrm{Co}_{9} \mathrm{~S}_{8} / \mathrm{AGF}$ (Fig. 5(c)) shows a typical type II adsorptiondesorption with $\mathrm{H} 4$ hysteresis isotherm that characterizes complex materials containing micropores and mesopores. The presence of micro- and mesopores in the composite material is supported by inset to Fig. 5(c) where a pore size distribution is observed around $3 \mathrm{~nm}$. Furthermore, the pore size distribution around $2 \mathrm{~nm}$ indicates the presence of micropores in this material. The formation of micropores in the composite can be attributed to the addition of AGF to the $\mathrm{Co}_{9} \mathrm{~S}_{8}$ material. The $\mathrm{N}_{2}$ absorption/desorption isotherms of $\mathrm{Co}_{9} \mathrm{~S}_{8}$, AGF and $\mathrm{Co}_{9} \mathrm{~S}_{8} / \mathrm{AGF}$ samples show that $\mathrm{Co}_{9} \mathrm{~S}_{8} / \mathrm{AGF}$ has a higher specific surface area of $787.9 \mathrm{~m}^{2} \mathrm{~g}^{-1}$ as compared to AGF with specific surface area of $498.2 \mathrm{~m}^{2} \mathrm{~g}^{-1}$ and $\mathrm{Co}_{9} \mathrm{~S}_{8}$ with specific surface area of $33.8 \mathrm{~m}^{2} \mathrm{~g}^{-1}$.

\section{Electrochemical characterization}

Furthermore, the $\mathrm{Co}_{9} \mathrm{~S}_{8}$ and $\mathrm{Co}_{9} \mathrm{~S}_{8} / \mathrm{AGF}$ materials prepared as electrodes were evaluated in a three-electrode configuration using $6 \mathrm{M} \mathrm{KOH}$ electrolyte for electrochemical supercapacitor. In electrochemical characterization, $\mathrm{CV}$ measurements are carried out to assess the macroscopic electrochemical surface reactions of the electrode material during supercapacitor operation. Fig. 6(a) shows a comparison of the CV curves obtained in a three-electrode cell for the $\mathrm{Co}_{9} \mathrm{~S}_{8}$ and $\mathrm{Co}_{9} \mathrm{~S}_{8} / \mathrm{AGF}$ electrodes at a scan rate of $50 \mathrm{mV} \mathrm{s}^{-1}$ in a potential window range of 0.0 to $0.5 \mathrm{~V} v s$. $\mathrm{Ag} / \mathrm{AgCl}$. For $\mathrm{Co}_{9} \mathrm{~S}_{8}$ electrode, there are two weak redox peaks at $\sim 0.15$ and $0.35 \mathrm{~V}$ which correspond to anodic and cathodic respectively, and these redox peaks are attributed to a reversible electron transfer process of the $\mathrm{Co}^{2+} /$ $\mathrm{Co}^{3+}$ redox couple. ${ }^{30}$ These redox peaks correspond to the conversion between different cobalt oxidation states, according to the following reaction equations:

$$
\begin{gathered}
\mathrm{Co}_{9} \mathrm{~S}_{8}+\mathrm{OH}^{-} \leftrightarrow \mathrm{Co}_{9} \mathrm{~S}_{8} \mathrm{OH}+\mathrm{e}^{-} \\
\mathrm{Co}_{9} \mathrm{~S}_{8} \mathrm{OH}+\mathrm{OH}^{-} \leftrightarrow \mathrm{Co}_{9} \mathrm{~S}_{8} \mathrm{O}+\mathrm{H}_{2} \mathrm{O}+\mathrm{e}^{-}
\end{gathered}
$$

Furthermore, the $\mathrm{Co}_{9} \mathrm{~S}_{8} / \mathrm{AGF}$ electrode also shows similar peaks. However, the $\mathrm{Co}_{9} \mathrm{~S}_{8} / \mathrm{AGF}$ electrode exhibited a better capacitive behaviour compared to the $\mathrm{Co}_{9} \mathrm{~S}_{8}$ and AGF electrodes as shown by the high current response of $\mathrm{Co}_{9} \mathrm{~S}_{8} /$ AGF electrode in Fig. 6(a), and therefore, further electrochemical characterization 

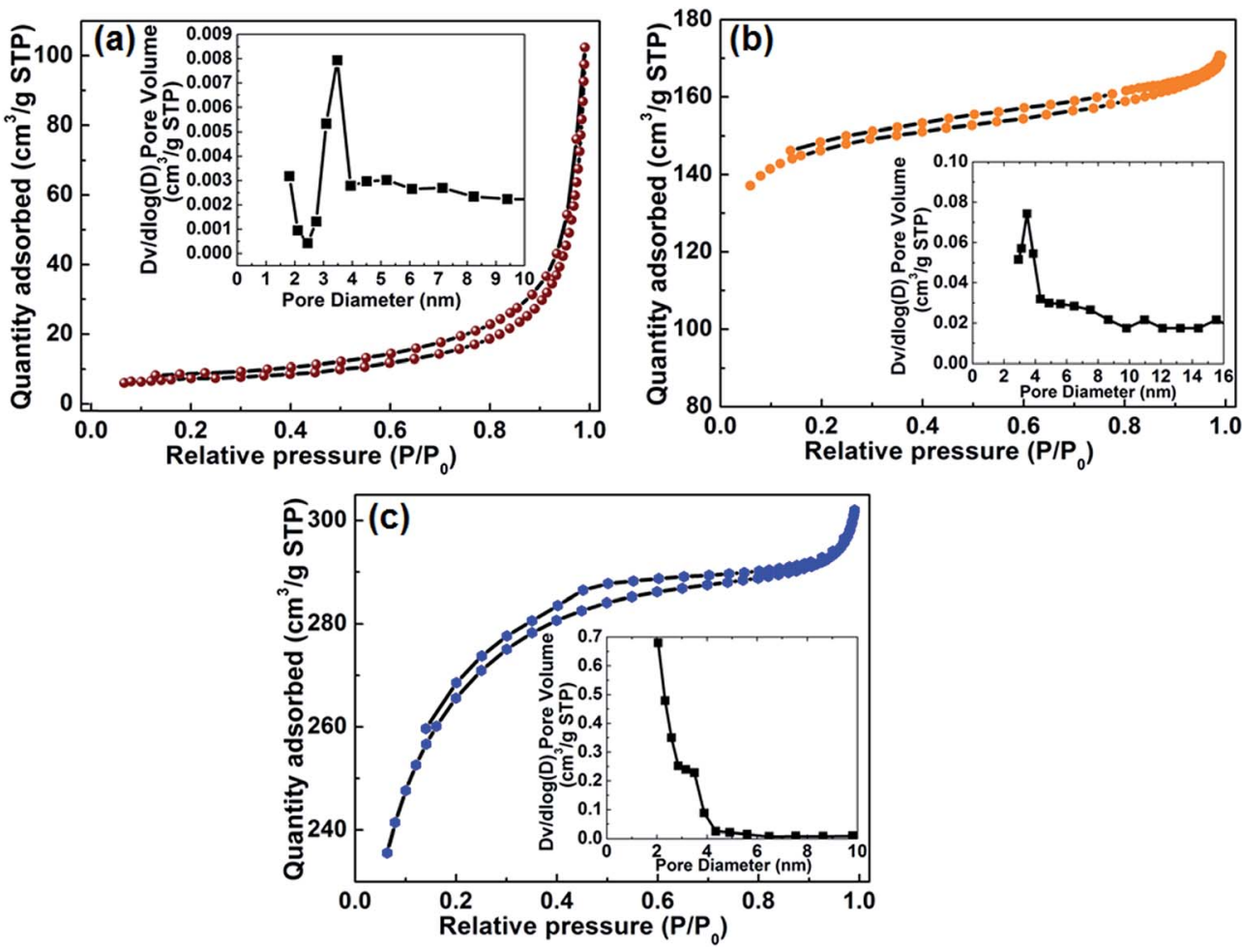

Fig. 5 (a) (b) and (c) $\mathrm{N}_{2}$ absorption/desorption isotherms of $\mathrm{Co}_{9} \mathrm{~S}_{8}, \mathrm{AGF}$ and $\mathrm{Co}_{9} \mathrm{~S}_{8} / \mathrm{AGF}$ samples respectively (insets show pore size distribution).

will focus only on the composite electrode. A high current response of $\mathrm{Co}_{9} \mathrm{~S}_{8} / \mathrm{AGF}$ compared to $\mathrm{Co}_{9} \mathrm{~S}_{8}$ electrode is due to the synergistic effect of $\mathrm{Co}_{9} \mathrm{~S}_{8}$ and AGF in the composite electrode. The CV curves of the $\mathrm{Co}_{9} \mathrm{~S}_{8}$ and $\mathrm{Co}_{9} \mathrm{~S}_{8} / \mathrm{AGF}$ electrodes both showing a high current response, and anodic and cathodic features indicate the pseudocapacitive behaviour of the electrodes. Of course, similar to metal-oxides, metal-sulphides also have pseudocapacitive behaviour due to sulphur ions in the metal sulphides owing to the fact that both sulphur and oxygen belong to the same group in the periodic table. Fig. 6(b) shows the $\mathrm{CV}$ curves of the $\mathrm{Co}_{9} \mathrm{~S}_{8} / \mathrm{AGF}$ electrode at different scan rates of $5,10,20,50$ and $100 \mathrm{mV} \mathrm{s}^{-1}$. These $\mathrm{CV}$ curves have similar shapes, however, the current response increases with increasing scan rates showing good capacitive feature of the electrode.

To demonstrate the effect of AGF in composite the specific capacitance $C_{\mathrm{sp}}\left(\mathrm{F} \mathrm{g}^{-1}\right)$ were calculated from the galvanostatic charge-discharge (GCD) and CV curves using the following equations:

$$
\begin{gathered}
C_{\text {sp }}=\frac{2 I \int V(t) \mathrm{d} t}{m V^{2}} \\
C_{\text {sp }}=\frac{1}{m \nu\left(V_{\mathrm{f}}-V_{\mathrm{i}}\right)} \int_{V_{\mathrm{i}}}^{V_{\mathrm{f}}} I(V) \mathrm{d} V
\end{gathered}
$$

where $I$ is the discharge current (A), $m$ is the mass of the electrode material $(\mathrm{g}), V$ is the potential window, $\nu$ is the scan rate $(\mathrm{V}$ $\left.\mathrm{s}^{-1}\right), V_{\mathrm{f}}$ and $V_{\mathrm{i}}$ are the integration potential limits of the CV curve $(\mathrm{V})$, and $I(V)$ is the $\mathrm{CV}$ current $(\mathrm{A})$.
Fig. 6(c) shows the galvanostatic charge-discharge (GCD) curves of $\mathrm{Co}_{9} \mathrm{~S}_{8} / \mathrm{AGF}$ electrodes at different current densities of $0.5,1,2,5$ and $10 \mathrm{~A} \mathrm{~g}^{-1}$. The discharge curves clearly show two voltage steps, a fast potential drop in the range of $0.5-0.33 \mathrm{~V}$ and a slow potential drop in the range of $0.33-0.26 \mathrm{~V}$. The voltage drop at around $0.33 \mathrm{~V}$ shows a faradic behaviour which is in agreement with the CV curves in Fig. 6(b). The plot of the specific capacitance as a function of scan rate and current density for $\mathrm{Co}_{9} \mathrm{~S}_{8}$ and $\mathrm{Co}_{9} \mathrm{~S}_{8} / \mathrm{AGF}$ electrodes is shown in Fig. 6(d) and (e), respectively. From all the results of $\mathrm{Co}_{9} \mathrm{~S}_{8} / \mathrm{AGF}$ composites including the pristine $\mathrm{Co}_{9} \mathrm{~S}_{8}$ the $\mathrm{Co}_{9} \mathrm{~S}_{8} / \mathrm{AGF}$ is showing the highest specific capacitance. A specific capacitance of $1150 \mathrm{~F} \mathrm{~g}^{-1}$ and $507 \mathrm{~F} \mathrm{~g}^{-1}$ was obtained for $\mathrm{Co}_{9} \mathrm{~S}_{8}$ and $\mathrm{Co}_{9} \mathrm{~S}_{8} / \mathrm{AGF}$ electrodes respectively at a scan rate of $5 \mathrm{mV} \mathrm{s}^{-1}$, and these specific capacitance values decreases as the scan rate increases as shown in Fig. 6(e). It is worth mentioning that at a low scan rate and current density in $\mathrm{KOH}$ electrolyte, negative ions $\left(\mathrm{OH}^{-}\right)$can easily diffuse into most active sites available through the electrode material leading to sufficient insertion reaction, however, at a high scan rate and current density, these ions have sufficient time to reach only the outer (surface) active sites of the electrode material and not the inner sites hence inner sites have no or little contribution to the capacitive behaviour of the electrode leading to a less capacitance. Fig. 6(d) and (e) clearly shows that the electrode with AGF has a high specific capacitance which is clear evidence that the incorporation of $\mathrm{AGF}$ in $\mathrm{Co}_{9} \mathrm{~S}_{8}$ provides better electrical conductivity due to improved metallic behaviour of the electrode. 

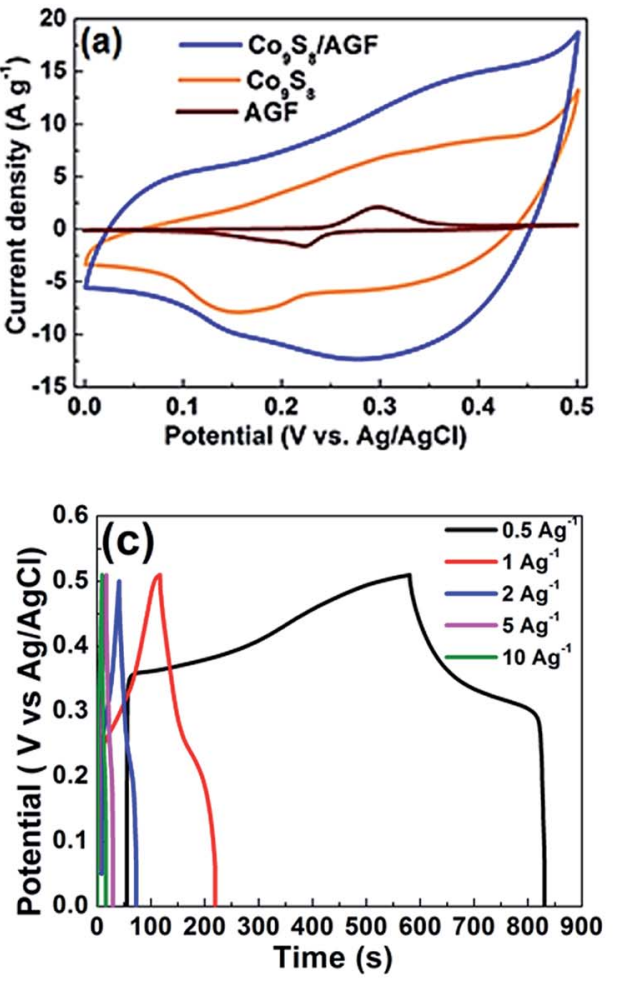
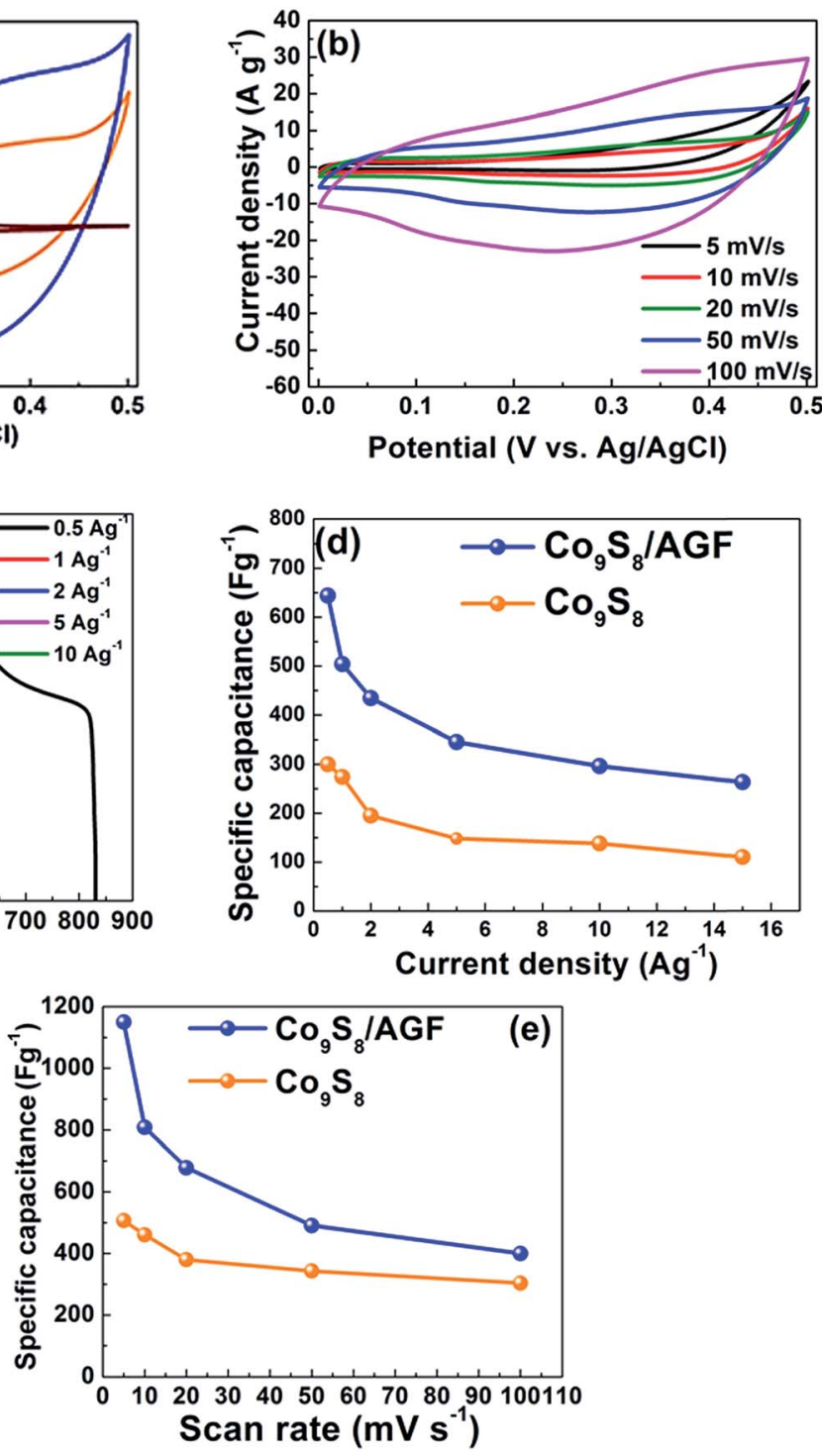

Fig. 6 (a) CV curves comparison of $\mathrm{Co}_{9} \mathrm{~S}_{8}, \mathrm{AGF}$ and $\mathrm{Co}_{9} \mathrm{~S}_{8} / \mathrm{AGF}$ electrodes at a scan rate of $50 \mathrm{mV} \mathrm{s}^{-1}$, (b) $\mathrm{CV}_{\text {curves of the Cog }} \mathrm{S}_{8} / \mathrm{AGF}$ electrode at

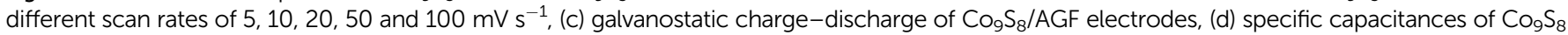
and $\mathrm{Co}_{9} \mathrm{~S}_{8} / \mathrm{AGF}$ electrodes as a function of current density and (e) specific capacitances of $\mathrm{Co}_{9} \mathrm{~S}_{8}$ and $\mathrm{Co}_{9} \mathrm{~S}_{8} / \mathrm{AGF}$ electrodes as a function of scan rate.

Furthermore, EIS measurements were carried out at an open circuit potential in a frequency range of $10 \mathrm{mHz}$ to 100 $\mathrm{kHz}$ to investigate the impedance behaviour at the electrode/ electrolyte interface. Fig. 7(a) shows the Nyquist plot (imaginary component, $Z^{\prime \prime} v s$. the real component, $Z^{\prime}$ of the impedance) of the $\mathrm{Co}_{9} \mathrm{~S}_{8}$ and $\mathrm{Co}_{9} \mathrm{~S}_{8} / \mathrm{AGF}$ electrodes, and the inset to the figure (magnified high-frequency region of the EIS) shows the equivalent series resistance (ESR - the combined resistance of electrolyte, intrinsic resistance of substrate and contact resistance at the active material/ current collector). This indicates that a composite electrode has a lower diffusion resistance compared to the pure electrode. In addition, the composite electrode displays a shorter diffusion length descriptive of the easiness of the movement of ions towards the electrode/electrolyte interface and the transfer of the charge to the electrode. EIS data of both electrodes show slightly tilted vertical lines indicating a deviation from ideal capacitive behaviour, but also suggesting low diffusion resistance of ions within the structure of the electrode material.

Fig. 7(b) show the equivalent circuit used for fitting the EIS data (solid-lines in Fig. 7(a)) using ZFIT software. ${ }^{31}$ The best fitting parameters of the EIS data are listed in Table 1 for both electrodes. In the circuit (Fig. 7(b)), the equivalent series resistance, $R_{\mathrm{S}}$ is in series with the constant phase element, $Q$, and charge transfer resistance, $R_{\mathrm{CT}}$. EIS data of the composite (Fig. 7(a)) shows a small or nearly semi-circular arc in the highfrequency to mid-frequency region which is modelled by $R_{\mathrm{CT}}$ and $Q$, and is accountable for the ideal capacitance of the electrode. In addition, this region (high-frequency to midfrequency) can be represented by the Warburg element which is expressed as Warburg impedance, $W$. 


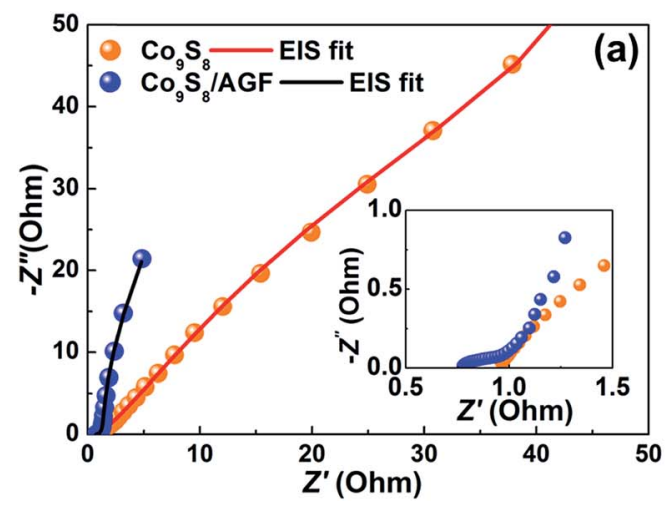

(b)

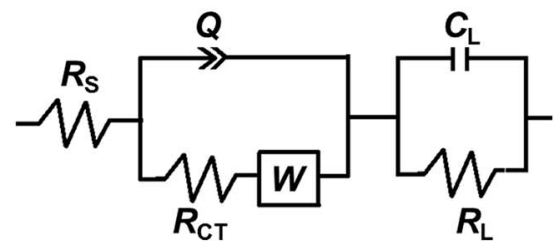

Fig. 7 (a) Nyquist plot (imaginary component, $Z^{\prime \prime}$ vs. the real component, $Z^{\prime}$ of the impedance) of the $\mathrm{Co}_{9} \mathrm{~S}_{8}$ and $\mathrm{Co}_{9} \mathrm{~S}_{8} / \mathrm{AGF}$ electrodes (the inset to the figure is a magnified high-frequency region of the plot). (b) The equivalent circuit used for fitting the EIS data in (a) as shown by solid lines.

Table 1 The equivalent circuit fitting parameters of EIS data for $\mathrm{CO}_{9} \mathrm{~S}_{8}$ and $\mathrm{CO}_{9} \mathrm{~S}_{8} / \mathrm{AGF}$ electrode

\begin{tabular}{llrlll}
\hline & \multicolumn{2}{l}{ Parameters } \\
\cline { 2 - 6 } materials & $R_{\mathrm{S}}(\Omega)$ & $R_{\mathrm{CT}}(\Omega)$ & $C_{\mathrm{L}}(\mathrm{F})$ & $N$ & $Q$ \\
\hline $\mathrm{Co}_{9} \mathrm{~S}_{8}$ & 0.94 & 14.16 & 1.0 & 0.91 & 1.0 \\
$\mathrm{Co}_{9} \mathrm{~S}_{8} / \mathrm{AGF}$ & 0.79 & 0.55 & 1.14 & 0.98 & 0.47
\end{tabular}

The Warburg impedance is formulated as $W=\frac{A}{\mathrm{j} \omega^{0.5}}$, where $A$ is the Warburg coefficient and $\omega$ is the angular frequency. ${ }^{32}$ Warburg impedance illustrates that the ion diffusion in the solution and the adsorption of ions onto the electrode surface occur swiftly. The impedance of the constant phase element $Q$, can be expressed as: $Q=\frac{1}{T(\mathrm{j} \omega)^{n}}$, where $T$ is the frequency independent constant with dimensions of ( $F$ $\left.\mathrm{cm}^{-2}\right)^{n}$ related to the roughness and pseudocapacitive kinetics of the electrode, $n$ value varies from -1 to 1 and can be calculated from the slope of the $\log Z v s . \log f \cdot{ }^{33}$ For values of $n=0, Q$ acts as a pure resistor while for $n=1, Q$ acts as a pure capacitor and for $n=-1, Q$ acts as an inductor. ${ }^{34}$
For very low-frequency values, an ideal electrode produces a vertical line parallel to the imaginary axis with a mass capacitance represented as $Q$. The deviation from this ideal behaviour is linked with a leakage resistance $R_{\mathrm{L}}$ which is parallel to the $C_{\mathrm{L}}$ in the equivalent circuit (Fig. 7(b)). In Table 1, the $R_{\mathrm{S}}$ and $R_{\mathrm{CT}}$ values $\left(R_{\mathrm{S}}=0.79 \Omega\right.$ and $\left.R_{\mathrm{CT}}=0.55 \Omega\right)$ show that a composite electrode has a lower diffusion resistance and charge-transfer resistance compared to a pure electrode $\left(R_{\mathrm{S}}=\right.$ $0.94 \Omega$ and $R_{\mathrm{CT}}=14.16 \Omega$ ). The $C_{\mathrm{L}}$-values (i.e., $\approx 1$ ) for both electrodes denotes the pseudocapacitance arising from the faradic charge transfer process. ${ }^{35}$

The $n$-values for $\mathrm{Co}_{9} \mathrm{~S}_{8}$ and $\mathrm{Co}_{9} \mathrm{~S}_{8} / \mathrm{AGF}$ electrodes (0.94 and 0.79 respectively) indicate a capacitive behaviour of the electrodes. The $\mathrm{Co}_{9} \mathrm{~S}_{8} / \mathrm{AGF}$ electrode shows low $Q$-value (0.47) compared to $\mathrm{Co}_{9} \mathrm{~S}_{8}$ electrode (1.0) indicating less deviation from ideal capacitive behaviour since an ideal electrode would produce a vertical line parallel to the imaginary axis. In brief, both $\mathrm{Co}_{9} \mathrm{~S}_{8}$ and $\mathrm{Co}_{9} \mathrm{~S}_{8} / \mathrm{AGF}$ electrodes show capacitive behaviour, however, the composite electrode outperforms the pure electrode clearly showing the electrochemical enhancing effect of AGF in the $\mathrm{Co}_{9} \mathrm{~S}_{8} / \mathrm{AGF}$ electrode.

Moreover, the cyclic stability of the electrode materials is an essential and important parameter to rank the performances of the energy storage applications. Fig. 8(a) shows the
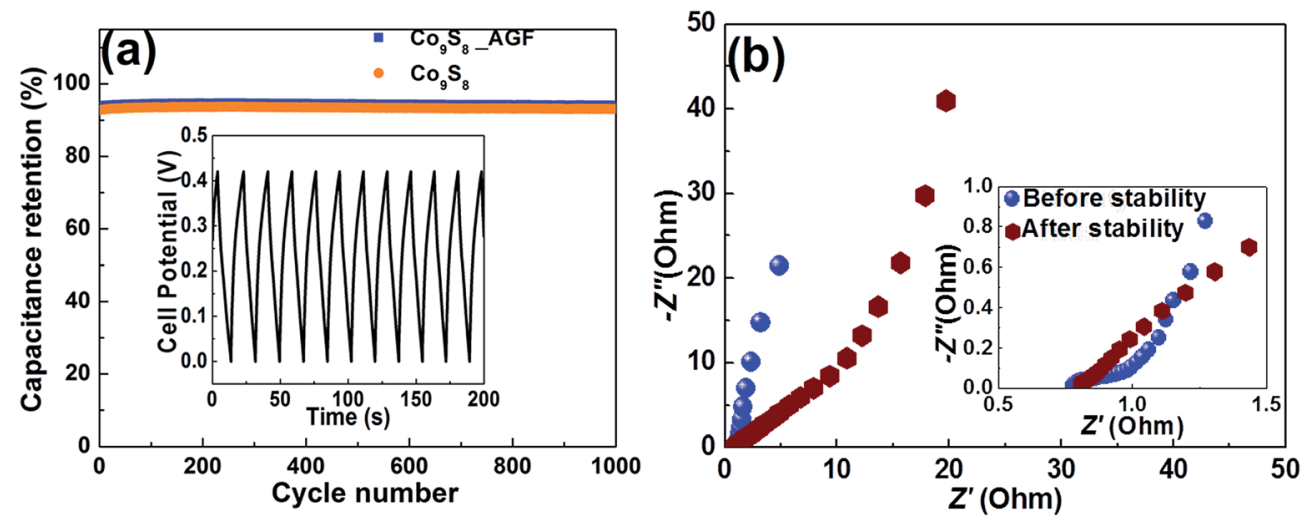

Fig. 8 (a) Cycling stability of the $\mathrm{CO}_{9} \mathrm{~S}_{8}$ and $\mathrm{CO}_{9} \mathrm{~S}_{8} / \mathrm{AGF}$ electrode at a current density of $4 \mathrm{~A} \mathrm{~g}^{-1}$ (inset shows the $1^{\text {st }} 200$ cyclic charge-discharge curves). (b) Nyquist plots of the $\mathrm{CO}_{9} \mathrm{~S}_{8} / \mathrm{AGF}$ electrode before and after 1000 charge-discharge cycles. 


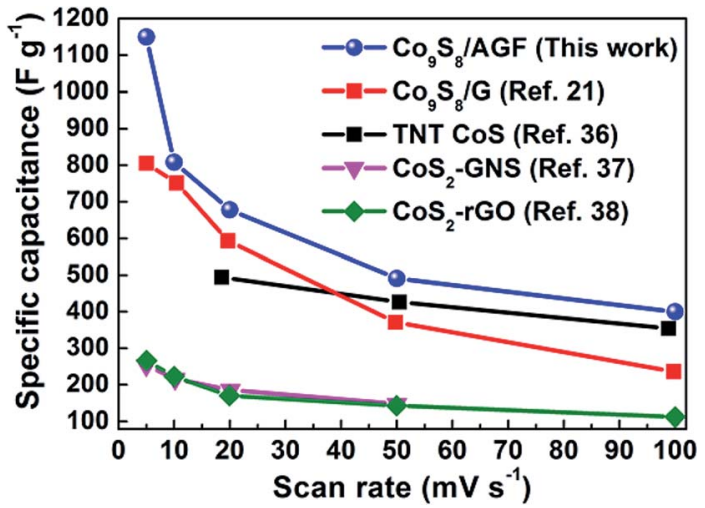

Fig. 9 A comparison of specific capacitance vs. scan rate of $\mathrm{CO}_{9} \mathrm{~S}_{8} /$ AGF composite electrode and those of cobalt sulphide-based composite electrodes reported by Ramachandran et al., ${ }^{21}$ Ray et al.. ${ }^{36}$ Wang et al., ${ }^{37}$ and Tang et al. ${ }^{38}$

electrochemical cycling stability of the $\mathrm{Co}_{9} \mathrm{~S}_{8}$ and $\mathrm{Co}_{9} \mathrm{~S}_{8} / \mathrm{AGF}$ electrode at a high current density of $4 \mathrm{~A} \mathrm{~g}^{-1}$ which depicts no obvious loss in the capacitance over 1000 charge-discharge cycles. The capacitance retention of the $\mathrm{Co}_{9} \mathrm{~S}_{8}$ is recorded at value of $93 \%$. However, capacitance retention of the $\mathrm{Co}_{9} \mathrm{~S}_{8} / \mathrm{AGF}$ electrode after 1000 cycles is $94 \%$ suggesting excellent rate stability of the electrode material. The excellent cycling stability of this electrode can be attributed to the nature of the $\mathrm{Co}_{9} \mathrm{~S}_{8}$ nanoparticles and the synergy between these particles and AGF in the composite which enhanced the cycling stability of the electrode material. This synergistic effect has predominantly improved the porous nature of the $\mathrm{Co}_{9} \mathrm{~S}_{8}$ resulting in ions utilizing most of the composite matrix, and also has significantly improved the electrical conductivity of the composite electrode resulting in a high current response of the electrode. Fig. 8(b) shows the Nyquist plots of the $\mathrm{Co}_{9} \mathrm{~S}_{8} /$ AGF electrode before and after cycling stability. After cycling stability, there is a slight change to the electrode material with the $R_{\mathrm{S}}$ value slightly increasing to $0.82 \Omega$, with an increase in diffusion path length attributed to the repeated cycling effect because of the high current density used.

In brief, this work have shown that a microwave-assisted synthesis of $\mathrm{Co}_{9} \mathrm{~S}_{8} / \mathrm{AGF}$ result in $\mathrm{Co}_{9} \mathrm{~S}_{8}$ nanoparticles clusters embedded in AGF matrix and this composite shows significant improvement on the specific capacitance compared to pure $\mathrm{Co}_{9} \mathrm{~S}_{8}$, even when compared to the specific capacitance values found in some of the previously published reports by other studies for cobalt sulphide-based composites, as shown in Fig. 9.

\section{Conclusions}

In this work, a microwave-assisted synthesis of $\mathrm{Co}_{9} \mathrm{~S}_{8} / \mathrm{AGF}$ composite showed $\mathrm{Co}_{9} \mathrm{~S}_{8}$ nanoparticles clusters embedded in AGF matrix. The incorporation of AGF into the $\mathrm{Co}_{9} \mathrm{~S}_{8}$ clearly improved the electrical conductivity and the electrochemical response of the $\mathrm{Co}_{9} \mathrm{~S}_{8} / \mathrm{AGF}$ electrode. This was indicated by the significant increase in the specific capacitance from $507 \mathrm{Fg}^{-1}$ ( $\mathrm{Co}_{9} \mathrm{~S}_{8}$ electrode) to $1150 \mathrm{~F} \mathrm{~g}^{-1}\left(\mathrm{Co}_{9} \mathrm{~S}_{8} / \mathrm{AGF}\right.$ electrode) at a scan rate of $5 \mathrm{mV} \mathrm{s}^{-1}$, and good cycling stability with $94 \%$ capacitance retention over 1000 charge-discharge cycles. The good electrochemical performance coupled with the low cost and simple preparation process focuses $\mathrm{Co}_{9} \mathrm{~S}_{8} / \mathrm{AGF}$ as a promising electrode for electrochemical supercapacitors application.

\section{Acknowledgements}

This work is based upon research supported by the South African Research Chairs Initiative (SARChI) of the Department of Science and Technology and National Research Foundation (NRF) of South Africa (Grant No. 61056). T. M. Masikhwa and M. J. Madito acknowledge financial support from the University of Pretoria and the NRF for their Postdoctoral fellowship.

\section{References}

1 C. Tan and H. Zhang, Chem. Soc. Rev., 2015, 44, 2713-2731. 2 J. P. Cheng, J. Zhang and F. Liu, RSC Adv., 2014, 4, 3889338917.

3 Y. Zhai, Y. Dou, D. Zhao, P. F. Fulvio, R. T. Mayes and S. Dai, Adv. Mater., 2011, 23, 4828-4850.

4 S. Bose, T. Kuila, A. K. Mishra, R. Rajasekar, N. H. Kim and J. H. Lee, J. Mater. Chem., 2012, 22, 767-784.

5 K. Hung, C. Masarapu, T. Ko and B. Wei, J. Power Sources, 2009, 193, 944-949.

6 C. Portet, J. Chmiola, Y. Gogotsi, S. Park and K. Lian, Electrochim. Acta, 2008, 53, 7675-7680.

7 A. Celzard, F. Collas, J. F. Marêché, G. Furdin and I. Rey, J. Power Sources, 2002, 108, 153-162.

8 T. C. Weng and H. Teng, J. Electrochem. Soc., 2001, 148, A368A373.

9 L. Zhang, H. Bin Wu and X. W. (David) Lou, Chem. Commun., 2012, 48, 6912-6914.

10 F. Luo, J. Li, H. Yuan and D. Xiao, Electrochim. Acta, 2014, 123, 183-189.

11 Q. Wang, L. Jiao, H. Du, J. Yang, Q. Huan, W. Peng, Y. Si, Y. Wang and H. Yuan, CrystEngComm, 2011, 13, 6960-6963.

12 P. Ilanchezhiyan, G. Mohan Kumar and T. W. Kang, J. Alloys Compd., 2015, 634, 104-108.

13 A. Ramadoss, T. Kim, G.-S. Kim and S. J. Kim, New J. Chem., 2014, 38, 2379-2385.

14 L.-Q. Fan, G.-J. Liu, C.-Y. Zhang, J.-H. Wu and Y.-L. Wei, Int. J. Hydrogen Energy, 2015, 40, 10150-10157.

15 H. Pang, C. Wei, X. Li, G. Li, Y. Ma, S. Li, J. Chen and J. Zhang, Sci. Rep., 2014, 4, 3577.

16 T. Zhu, Z. Wang, S. Ding, J. S. Chen and X. W. D. Lou, RSC Adv., 2011, 1, 397-400.

17 A. Wang, H. Wang, S. Zhang, C. Mao, J. Song, H. Niu, B. Jin and Y. Tian, Appl. Surf. Sci., 2013, 282, 704-708.

18 C. J. Raj, B. C. Kim, W.-J. Cho, W.-G. Lee, Y. Seo and K.-H. Yu, J. Alloys Compd., 2014, 586, 191-196.

19 W. Shi, J. Zhu, X. Rui, X. Cao, C. Chen, H. Zhang, H. H. Hng and Q. Yan, ACS Appl. Mater. Interfaces, 2012, 4, 2999-3006.

20 L. Yin, L. Wang, X. Liu, Y. Gai, L. Su, B. Qu and L. Gong, Eur. J. Inorg. Chem., 2015, 2015, 2457-2462.

21 R. Ramachandran, M. Saranya, C. Santhosh, V. Velmurugan, B. P. C. Raghupathy, S. K. Jeong and A. N. Grace, RSC Adv., 2014, 4, 21151-21162. 
22 J. Yu, H. Wan, J. Jiang, Y. Ruan, L. Miao, L. Zhang, D. Xia and K. Xu, J. Electrochem. Soc., 2014, 161, A996-A1000.

23 R. Jin, J. Liu, Y. Xu, G. Li and G. Chen, J. Mater. Chem. A, 2013, 1, 7995-7999.

24 J. Yang, Y. Zhang, C. Sun, G. Guo, W. Sun, W. Huang, Q. Yan and X. Dong, J. Mater. Chem. A, 2015, 3, 11462-11470.

25 Y. Zhang, M. Ma, J. Yang, C. Sun, H. Su, W. Huang and X. Dong, Nanoscale, 2014, 6, 9824-9830.

26 A. Bello, F. Barzegar, D. Momodu, J. Dangbegnon, F. Taghizadeh and N. Manyala, Electrochim. Acta, 2015, 151, 386-392.

27 S. Geller, Acta Crystallogr., 1962, 15, 1195-1198.

28 P. A. Denis, R. Faccio and A. W. Mombru, ChemPhysChem, 2009, 10, 715-722.

29 L. Xu, Y.-S. Ding, C.-H. Chen, L. Zhao, C. Rimkus, R. Joesten and S. L. Suib, Chem. Mater., 2007, 20, 308-316.

30 J. Pu, Z. Wang, K. Wu, N. Yu and E. Sheng, Phys. Chem. Chem. Phys., 2014, 16, 785-791.
31 B. E. Conway, Electrochemical Supercapacitors: Scientific Fundamentals and Technological Applications, Kluwer Academic/Plenum, New York, 1999.

32 Y. Zhou, H. Xu, N. Lachman, M. Ghaffari, S. Wu, Y. Liu, A. Ugur, K. K. Gleason, B. L. Wardle and Q. M. Zhang, Nano Energy, 2014, 9, 176-185.

33 D. Pech, M. Brunet, H. Durou, P. Huang, V. Mochalin, Y. Gogotsi, P.-L. Taberna and P. Simon, Nat. Nanotechnol., 2010, 5, 651-654.

34 C. Masarapu, H. F. Zeng, K. H. Hung and B. Wei, ACS Nano, 2009, 3, 2199-2206.

35 H. Guan, L.-Z. Fan, H. Zhang and X. Qu, Electrochim. Acta, 2010, 56, 964-968.

36 R. S. Ray, B. Sarma, A. L. Jurovitzki and M. Misra, Chem. Eng. J., 2015, 260, 671-683.

37 B. Wang, J. Park, D. Su, C. Wang, H. Ahn and G. Wang, J. Mater. Chem., 2012, 22, 15750-15756.

38 J. Tang, J. Shen, N. Li and M. Ye, Ceram. Int., 2014, 40, 1541115419. 